\title{
Encefalopatía pancreática, un diagnóstico a considerar. Presentación de un caso
}

\section{RESUMEN}

La encefalopatía pancreática es una complicación sistémica rara en pacientes con pancreatitis aguda, generalmente se presenta en los estadios tempranos de un cuadro grave de pancreatitis aguda y tiene una tasa de mortalidad hasta de $57 \%$. Describimos el caso clínico de una paciente de 16 años de edad que tuvo alteraciones neurológicas durante la evolución de un cuadro de pancreatitis aguda. Se descartaron otras posibles causas y se consideró el diagnóstico de encefalopatía pancreática. Discutimos los factores clínicos y de laboratorio asociados con la presentación de esta complicación, así como la relación entre moléculas proinflamatorias y su papel como neuromoduladores en el sistema nervioso central de estos pacientes.

Palabras clave: encefalopatía pancreática, pancreatitis aguda en niños.

\section{Pancreatic encephalopathy, a case report}

\begin{abstract}
Pancreatic encephalopathy (PE) is an uncommon complication of acute pancreatitis. PE, one of multiple organ dysfunction syndromes; generally occurs in the early stage of severe acute pancreatitis and has a high mortality of $57 \%$. We report a 16 years old female patient who presented neurological symptoms during an episode of acute pancreatitis. Other etiologies were discarded, and PE was considered. We discuss clinical and laboratorial factors associated with this complication. We also discuss about the role of pro-inflammatory molecules as neuromodulators within the central nervous system during the evolution of patients with acute pancreatitis.
\end{abstract}

Key words: pancreatic encephalopathy, acute pediatric pancreatitis.
Karla Lorena Chávez-Acosta ${ }^{1}$

Sandra Lizárraga-López ${ }^{2}$

Patricia Zárate-Castañón ${ }^{2}$

Roberto García-Navarrete ${ }^{3}$

${ }^{1}$ Departamento de Pediatría.

${ }^{2}$ Unidad de Terapia Intensiva.

${ }^{3}$ Departamento de Neurocirugía.

Instituto Nacional de Pediatría, Ciudad de México.
Recibido: 21 de marzo del 2014

Aceptado: 9 de febrero del 2015

Correspondencia: Dra. Karla Lorena ChávezAcosta

Insurgentes Sur 3700-C

CP 04530 México, D.F.

karlalcha@hotmail.com

Este artículo debe citarse como

Chávez-Acosta KL, Lizárraga-López S, Zárate-Castañón P, García-Navarrete R. Encefalopatía pancreáti$\mathrm{ca}$, un diagnóstico a considerar. Presentación de un caso. Acta Pediatr Mex 2015;36:337-346. 


\section{INTRODUCCIÓN}

En los últimos años se ha descrito un incremento en la incidencia de pancreatitis aguda en niños y adultos. Los estudios en niños, a escala mundial, señalan una incidencia de 0.7 hasta seis casos por 10000 niños, mayormente en escolares y por lo general asociada con enfermedad sistémica. En México existen pocos casos; sin embargo, en el Hospital de Pediatría del Centro Médico Nacional Siglo XXI, Rojas y sus colaboradores informaron de cinco casos en un periodo de seis meses. En 2008, en el Hospital Infantil de México Federico Gómez, se registraron 16 casos en 10000 egresos hospitalarios, una de las tasas más altas reportadas, muy probablemente asociados con el uso de medicamentos como la L-asparaginasa por el aumento en la frecuencia de padecimientos oncológicos que son tratados en este tipo de centros de referencia nacional. ${ }^{1}$

Etxeberria y sus colegas definieron a la pancreatitis aguda como un proceso inflamatorio que causa aumento en la concentración de enzimas pancreáticas con respuestas inflamatorias local y sistémica y compromiso variable de órganos y sistemas distantes. ${ }^{2}$ Para el diagnóstico de esta afección se requieren dos de los siguientes tres parámetros: dolor abdominal, elevación $\geq 3$ veces de los valores normales de amilasa o lipasa y estudios de imagen con datos compatibles con pancreatitis (edema pancreático, necrosis pancreática o peripancreática, inflamación peripancreática, colección aguda de líquido, hemorragia o absceso pancreático y seudoquiste pancreático). ${ }^{3}$ Las principales causas de pancreatitis aguda en pediatría son traumatismos, alteraciones anatómicas del sistema biliar, infecciosas (virus, bacterias, hongos, parásitos), enfermedades sistémicas, enfermedades hereditarias y metabólicas; además de fármacos, entre los más frecuentes los antineoplásicos. ${ }^{4-5}$

Las complicaciones derivadas de la pancreatitis aguda aparecen en la fase temprana durante los primeros 15 días de evolución de la enfermedad. La mortalidad debida a las complicaciones depende del órgano afectado, asociación con necrosis y proceso séptico, alcanzando 25 a $50 \%$ en los pacientes con pancreatitis aguda necrosante, con tasa global de mortalidad de la enfermedad de $5 \%{ }^{2,6-10}$ (Cuadro 1 ).

Entre las complicaciones más graves se encuentra la encefalopatía pancreática que se caracteriza por disminución del estado de alerta (puntuación en la escala de coma de Glasgow menor de 14) durante la evolución de la pancreatitis aguda grave. Además, alteraciones del comportamiento: agitación sicomotriz, euforia, confusión, crisis convulsivas focales o generalizadas, alteraciones inespecíficas en el electroencefalograma; tomografía computada de cráneo normal y disociación albumino-citológica en líquido cefalorraquídeo. ${ }^{11,12}$ La encefalopatía pancreática es una complicación rara y muy poco reportada, con una incidencia estimada cercana a $11 \%$ en pacientes pediátricos con pancreatitis aguda grave. ${ }^{13,14}$

Keilchi y Akinobu realizaron estudios experimentales en los que se observaron proteínas secretoras asociadas con el proceso de pancreatitis aguda (pancreatitis associated proteins, $\mathrm{PAP})$. Estas proteínas provocan aumento de citocinas como TNF- $\alpha$, IL-6 e IL-1b, ocasionan una respuesta inflamatoria intensa que involucra órganos extraabdominales como el sistema nervioso central y desencadena un cuadro de encefalopatía. ${ }^{15,16}$

El factor de necrosis tumoral $\alpha$ ha cobrado una gran relevancia en el estudio de la pancreatitis aguda, relacionándosele con el pronóstico, riesgo de sepsis y de mortalidad. Dentro de sus funciones se le identifica como una citocina con efectos pleiotrópicos sobre el sistema inmunológico. ${ }^{17}$ En el campo de las neurociencias se le ha vinculado con una gran variedad de procesos neuropatológicos como isquemia, neurotrauma 
Chávez-Acosta KL et al. Encefalopatía pancreática

Cuadro 1. Complicaciones más frecuentes de la pancreatitis aguda

\begin{tabular}{|c|c|c|}
\hline Complicación & $\%$ & Definición operacional \\
\hline Insuficiencia respiratoria aguda & $25-48$ & $\begin{array}{l}\mathrm{PaO}_{2} \leq 60 \mathrm{mmHg} \text { bajo respiración espontánea de aire ambiental. Derrame } \\
\text { pleural en } 15 \%\end{array}$ \\
\hline Insuficiencia renal aguda & $5-28$ & $\begin{array}{l}\text { Creatinina sérica }>2 \mathrm{mg} / \mathrm{dL} \text { tras una adecuada rehidratación u oliguria } \\
<30 \mathrm{~mL} \text { en } 3 \text { horas o } 700 \mathrm{~mL} \text { en } 24 \text { horas }\end{array}$ \\
\hline Estado de choque & $15-22$ & $\begin{array}{l}\text { Presión arterial sistólica menor a } 90 \mathrm{mmHg} \text { que necesita aminas vaso- } \\
\text { presoras }\end{array}$ \\
\hline Disfunción multiorgánica & 20 & $\begin{array}{l}\text { Signos de sepsis asociados con insuficiencia de } 2 \text { o más órganos. Tiene } \\
\text { que ser persistente, al menos más de } 3 \text { días bajo tratamiento médico } \\
\text { intensivo. Acidosis metabólica, coagulopatía }(\text { TPT }<50 \% \text { y plaquetas } \\
<100000 / \mathrm{mm}^{3} \text { ) y encefalopatía }(G \text { lasgow }<14 \text { ) }\end{array}$ \\
\hline Sepsis extrapancreática & $40-70$ & $\begin{array}{l}\text { Puede ser de origen pulmonar, urinario, gastrointestinal u otros. Gérmenes } \\
\text { más comunes: bacilos gramnegativos, cocos grampositivos }\end{array}$ \\
\hline Coagulación intravascular diseminada & $2-10$ & $\begin{array}{l}\mathrm{TP}<70 \% \text {, plaquetas }<100000 / \mathrm{mm}^{3} \text {, hipofibrinogenemia }<100 \mathrm{mg} / \mathrm{dL} \\
\text { y dímero } \mathrm{D}>250 \mathrm{ng} / \mathrm{mL}\end{array}$ \\
\hline Hiperglucemia & 4 & $\begin{array}{l}\text { Glucemia }>120 \mathrm{mg} / \mathrm{dL} \text { de forma persistente y que necesita insulina } \\
\text { terapéutica para su control }\end{array}$ \\
\hline Hipocalcemia & 25 & $\begin{array}{l}\text { Calcio en suero }<8 \mathrm{mg} / \mathrm{dL} \text { de forma persistente y que requiere calcio } \\
\text { terapéutico. }\end{array}$ \\
\hline Hemorragia gastrointestinal & 2 & $\begin{array}{l}\text { Hematemesis o melena (sangrado de tubo digestivo alto o bajo) }>250 \mathrm{~mL} \\
\text { en una vez o }>500 \mathrm{~mL} / 24 \text { horas }\end{array}$ \\
\hline Encefalopatía pancreática & 11 & $\begin{array}{l}\text { Glasgow < } 14 \text { durante la fase aguda de la pancreatitis aguda grave. } \\
\text { Agitación psicomotriz. Electroencefalograma inespecífico. Estudios } \\
\text { de imagen normales. Líquido cefalorraquídeo: disociación albumino- } \\
\text { citológica. Deben excluirse el síndrome de abstinencia alcohólica y la } \\
\text { encefalopatía hepática }\end{array}$ \\
\hline Otras alteraciones metabólicas & & $\begin{array}{l}\text { Acidosis hiperosmolar, hipoglucemia, hipofosfatemia, hipernatremia, } \\
\text { alteraciones secundarias a la sepsis o al estado de choque }\end{array}$ \\
\hline
\end{tabular}

y toxicidad mediada por neurotransmisores excitadores. ${ }^{18-20}$ En los últimos años se ha demostrado que, además de los efectos reconocidos sobre la viabilidad celular, posee propiedades que en el sistema nervioso central producen cambios rápidos en la excitabilidad neuronal. ${ }^{21}$ Cuando existen alteraciones patológicas que se acompañan de incrementos de otras citocinas proinflamatorias como la IL-1b, los efectos biológicos pueden ser mediados por receptores expresados de forma constitutiva en células de la glía o células endoteliales de la barrera hematoencefálica. ${ }^{22-25}$ De esta forma, y de acuerdo con sus posibles efectos neuromoduladores, el factor de necrosis tumoral $\alpha$ y la IL-1b pueden afectar funciones mentales y disminuir el umbral para crisis convulsivas al modificar la permeabilidad de la barrera hematoencefálica y la excitabilidad neuronal, respectivamente. ${ }^{26}$

La importancia de esta enfermedad radica en su consideración como diagnóstico diferencial al presentarse en un paciente pediátrico con cuadro clínico de encefalopatía asociado con pancreatitis aguda en presencia de factores de riesgo (activación pancreática, incremento en la producción de radicales libres y citocinas, anormalidades en la microcirculación, alteraciones hemodinámicas, hipoxemia, infección bacteriana, desequilibrio hídrico o electrolítico y deficiencia de vitamina B1). ${ }^{27}$ El reconocimiento temprano puede disminuir la morbilidad y la mortalidad, así como dar pauta para realizar estudios complementarios como la tomografía 
de cráneo y el electroencefalograma como parte del manejo integral, sobre todo en los pacientes que reciben antineoplásicos o esteroides. Los informes de encefalopatía pancreática en niños son escasos, lo que los convierte en un tema con muchas posibilidades en enseñanza e investigación.

\section{CASO CLÍNICO}

Mujer de 16 años de edad con diagnóstico de leucemia linfoblástica aguda pre $\mathrm{B}$ de alto riesgo por su edad. Como antecedente de importancia, siete días antes de su ingreso, recibió un primer ciclo de quimioterapia con L-asparaginasa en dosis de $14500 \mathrm{UI} /$ día durante 5 días, vincristina 2 mg (1 dosis) e hidrocortisona en base a prednisona equivalente a $60 \mathrm{mg} /$ día durante 7 días. A su ingreso presentó dolor abdominal intenso, de inicio súbito, en mesogastrio, con irradiación hacia la espalda, incapacitante, escala visual análoga de dolor 8/10, acompañado de náusea y evacuaciones semilíquidas. En la exploración física se observó abdomen distendido, dolor a la palpación media en epigastrio y resistencia muscular. Los resultados de laboratorio de su ingreso fueron: glucosa de $100 \mathrm{mg} / \mathrm{dL}$, calcio sérico $8.7 \mathrm{mg} / \mathrm{mL}$, amilasa y lipasa $611 \mathrm{mg} / \mathrm{dL}$ y $819 \mathrm{mg} / \mathrm{dL}$, respectivamente. Un ultrasonido abdominal mostró edema en la cabeza y el cuello del páncreas, abundante líquido peripancreático y esteatosis hepática. La tomografía de abdomen reveló edema en el tejido peripancreático, además de necrosis en cabeza y cuello del páncreas, lo que permitió clasificar la pancreatitis como Baltazar E. ${ }^{28}$

Horas después de su llegada a urgencias presentó datos de choque hipovolémico con hipotensión, oliguria, acidosis metabólica, hiperlactatemia, hipocalcemia e hiponatremia; ingresó a la Unidad de Terapia Intensiva Pediátrica. Ameritó soporte ventilatorio mecánico durante siete días por datos de daño pulmonar agudo mediante radiografía de tórax, con datos de fuga capilar a intersticio pulmonar e hipoxemia y saturación arterial de oxígeno $\left(\mathrm{SaO}_{2}\right)$ de $55 \%$. Se corrigió la hiponatremia y se inició administración de antibióticos con cefepima y metronidazol para cobertura del proceso intraabdominal. Como parte del manejo del cuadro de pancreatitis se indicaron ayuno, soluciones calculadas en bolo con expansores de volumen como albumina de forma inicial y posteriormente líquidos de mantenimiento; analgesia con buprenorfina y ketorolaco, además de suspenderse la dexametasona que, como se mencionó anteriormente, fue indicada como parte del manejo antineoplásico. Al mostrar mejoría hemodinámica se inició nutrición parenteral.

Al octavo día de estancia en terapia intensiva se logró extubación programada al presentar mejoría en las condiciones ventilatorias y hemodinámicas; sin embargo, persistió poco reactiva al medio a pesar de suspender sedación previa a extubación. Durante el día 13 del internamiento hubo, de forma súbita, agitación psicomotriz, alucinaciones visuales y disminución en la escala de coma de Glasgow a 12 puntos, seguidas de crisis convulsivas caracterizadas por falta de interacción con el medio, supraversión ocular hacia la derecha y movimientos clónicos hemicorporales izquierdos de dos minutos de duración. Fue tratada con dos bolos de diazepam de $0.1 \mathrm{mg} /$ $\mathrm{kg} /$ dosis, impregnación con difenilhidantoína de $20 \mathrm{mg} / \mathrm{kg} /$ dosis y mantenimiento con $7 \mathrm{mg} / \mathrm{kg} /$ día. Después del evento se descartaron anormalidades metabólicas y electrolíticas obteniendo perfil bioquímico y concentraciones de amonio normales. La tomografía de cráneo documentó reforzamiento de la corteza cerebral y cerebelosa sin datos de sangrado agudo, masa intracraneal u otra lesión (Figura 1). El electroencefalograma mostró actividad de base lenta de predominio frontal con atenuación en derivaciones posteriores (Figura 2). 


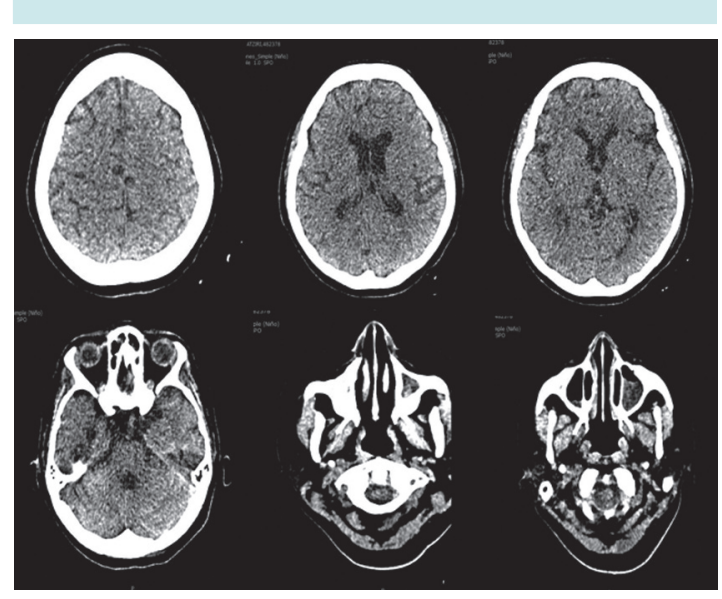

Figura 1. Tomografía: parénquima cerebral sin evidencia de lesiones focales ni difusas. Llama la atención dilatación quística del espacio aracnoideo a nivel de la punta del temporal en el lado izquierdo. A nivel de los senos paranasales ocupación etmoidomaxilar bilateral de predominio izquierdo.

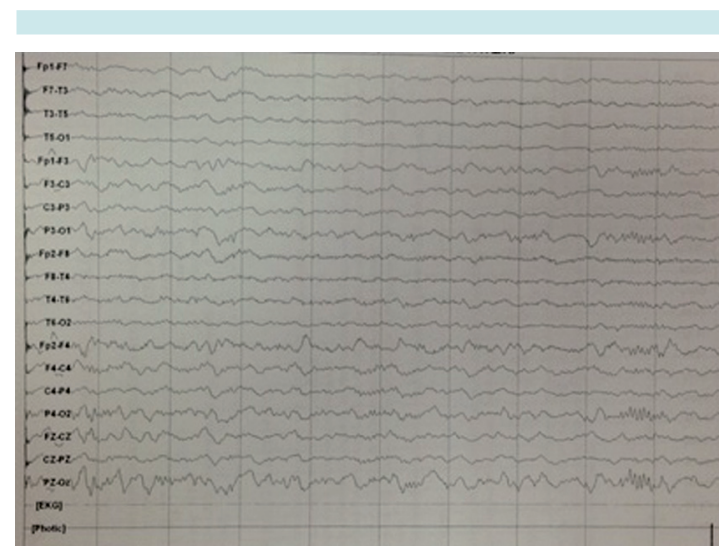

Figura 2. Electroencefalograma: actividad de base lenta para la edad de la paciente. Atenuación de la actividad funcional y del voltaje en la región occipital bilateral.

Ante la sospecha de infiltración neoplásica al sistema nervioso central por una afección de base se realizó punción lumbar que reportó presión de apertura normal, líquido cefalorraquídeo transparente, glucosa de $67 \mathrm{mg} / \mathrm{dL}$ (sérica en ese momento de $102 \mathrm{mg} / \mathrm{dL}$ ), proteínas $22 \mathrm{mg} / \mathrm{dL}$, células escasas y sin blastos. La tinción de Gram no documentó microorganismos y los cultivos bacterianos y virales se reportaron negativos: incluyendo Streptococcus pneumoniae, Neisseria meningitidis, Mycobacterium tuberculosis, enterovirus, herpes virus, virus Epstein-Barr, varicela, influenza, adenovirus y hepatitis.

Se realizó resonancia magnética en la que se identificó discreta atrofia cerebral cortico-subcortical, aspecto adelgazado generalizado de las arterias cerebrales, de tipo inespecífico y engrosamiento mucoso etmoidal, algunas celdillas mastoideas ocupadas por líquido y quiste aracnoideo temporal izquierdo. No se encontraron datos compatibles con isquemia, hemorragia o hipoxia. Se consideró poco probable la relación entre el quiste aracnoideo y la sintomatología del paciente (Figura 3). El servicio de neurología concluyó cuadro clínico compatible con síndrome encefálico y sugirió retirar buprenorfina para reevaluar. La paciente continuó con episodios de crisis convulsivas durante 6 días a pesar de haber concluido tiempo de vida media del medicamento en el sistema nervioso central (i.e. 6 horas). Posteriormente, con mejoría gradual en el estado de alerta, el día 20 de su estancia en terapia intensiva ya no tuvo convulsiones y hacia el día 25 mostró integridad neurológica de 15 puntos en la escala de coma de Glasgow.

\section{DISCUSIÓN}

Entre los diagnósticos diferenciales del paciente con cuadro clínico compatible con encefalopatía, y que simultáneamente presenta pancreatitis aguda, es importante considerar los siguientes datos: isquemia cerebral secundaria a hipotensión, estado hiperosmolar, hipocalcemia o acidosis metabólica por diabetes secundaria a la pancreatitis. Así mismo, se deben excluir encefalitis infecciosa, síndrome neuroléptico maligno, encefalopatía metabólica o tóxica, 
lesión ocupativa intracraneal, hemorragia o isquemia intracraneal e infiltración tumoral, entre otros. Del espectro de enfermedades que pudieran dar pie a los síntomas neurológicos se fueron descartando de acuerdo con los antecedentes y con la frecuencia de presentación en la edad pediátrica (Cuadro 2)..$^{29-38}$

Decidimos descartar hemorragia o isquemia intracraneal debido a que son causas comunes que inician clínicamente de manera súbita con dolor de cabeza seguido de pérdida progresiva de funciones neurológicas (debilidad, hemiparesia, pérdida del habla o de la visión y confusión). También son frecuentes las náuseas, vómitos, crisis convulsivas y pérdida de consciencia que pueden ocurrir en pocos minutos. Con la tomografía de cráneo se descartaron isquemia, sangrado, neoplasia intracraneal y trombosis; en la resonancia magnética de encéfalo se identificó atrofia cortico-subcortical, un quiste aracnoideo temporal izquierdo, sinusitis etmoidal y maxilar bilateral (Figura 3).

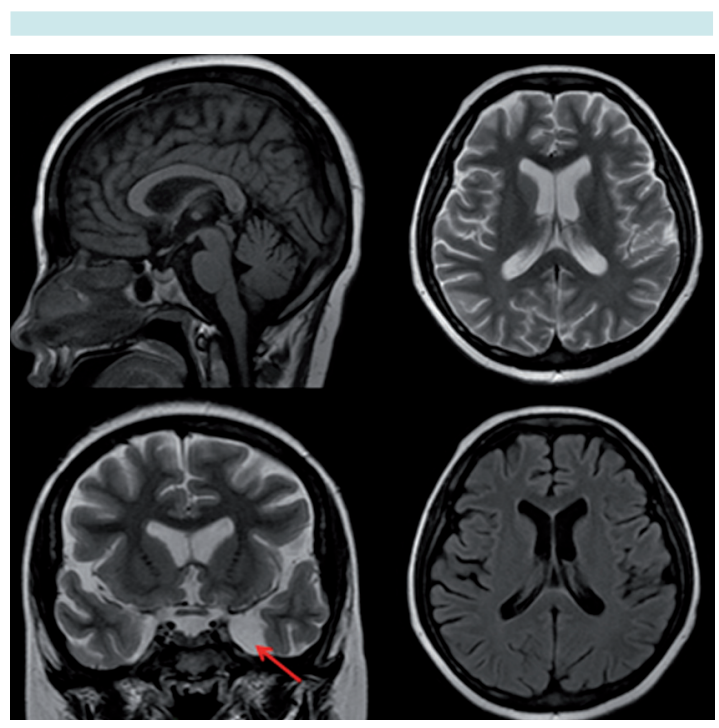

Figura 3. Resonancia magnética: disminución del volumen cerebral córtico-subcortical en relación con atrofia. Incidentalmente se observa un pequeño quiste aracnoideo en la fosa temporal izquierda (flecha).
El principal factor de riesgo para la encefalopatía pancreática en la edad pediátrica es la pancreatitis aguda grave que puede ser desencadenada por obstrucción o sobredistención del conducto pancreático, fármacos, hipercalcemia, incremento en la permeabilidad del conducto pancreático, isquemia, infecciones virales o bacterianas e hiperestimulación de la glándula. Estos factores inician una inapropiada activación de los gránulos de cimógeno por las hidroxilasas pancreáticas con la consecuente isquemia del órgano. Puede presentarse desde un cuadro de dolor abdominal leve a moderado hasta una forma grave hemorrágica o necrosante con el consecuente aumento de las enzimas pancreáticas en la sangre que pueden desencadenar el proceso inflamatorio en el sistema nervioso central que se manifiesta clínicamente como encefalitis. $^{39}$

La encefalopatía esteroidea debida a la administración de corticoesteroides produce con frecuencia efectos adversos entre los que se cuentan síntomas neuropsiquiátricos, desde cuadros de psicosis, manía o depresión hasta alteraciones cognitivas similares a las que se ven en los cuadros demenciales. La incidencia de estos problemas oscila entre 3 y $6 \%$ y son más frecuentes en mujeres con una relación de 2:1. La aparición de síntomas es, por lo general, entre el tercero y el undécimo día después de iniciado el tratamiento y es dependiente de la dosis utilizada. Según los datos aportados por el Boston Collaborative Drug Surveillance Program las manifestaciones neuropsiquiátricas aparecieron en $1.3 \%$ de 463 pacientes tratados con $40 \mathrm{mg} /$ día o menos de prednisona, fueron observadas en $4.6 \%$ de 175 pacientes que recibían dosis de entre 40 y $80 \mathrm{mg} /$ día mientras que para dosis mayores de $80 \mathrm{mg} /$ día la incidencia fue de 18.4\% en 38 pacientes. ${ }^{40}$ Aunque la paciente recibió esteroides el cuadro fue de instalación súbita, sin clínica psiquiátrica; sus principales síntomas fueron crisis convulsivas que no se han descrito como parte de la encefalopatía por esteroides. 
Chávez-Acosta KL et al. Encefalopatía pancreática

Cuadro 2. Diagnósticos diferenciales

\section{Diagnóstico diferen- Método de exclusión cial}

Encefalitis

Encefalopatía tóxica

Encefalopatía metabólica

Lesión ocupativa intracraneal

Hemorragia o isquemia intracraneal

Infiltración tumoral
Definición: la encefalitis es un proceso inflamatorio del sistema nervioso central asociado con evidencia clínica de disfunción neurológica; varios agentes incluidos: virus, bacterias, hongos. Clínica: alteraciones del comportamiento u otros síntomas neurológicos como déficits motores (ataxia y otras alteraciones del movimiento), alteración de pares craneales, parestesias, convulsiones, somnolencia o letargia que, en casos graves, progresa a coma y muerte.

Exclusión: líquido cefalorraquídeo normal y agentes virales en LCR normales.

Definición: afección del SNC o del SNP por un error congénito del metabolismo intermediario (aminoacidopatías, acidurias orgánicas, trastornos del ciclo de la urea e intolerancia a los azúcares), enfermedades lisosomales (esfingolipidosis, glucoproteinosis, mucopolisacaridosis), trastornos peroxisomales y trastornos en producción de energía (glucogenosis, defectos en la oxidación de los ácidos grasos y enfermedades mitocondriales).

Clínica: la edad de presentación puede variar, aunque su incidencia es más elevada en el periodo neonatal. Se presenta con hipoxia, infección o hemorragia cerebral, patología cardiopulmonar. Irritabilidad, letargia o coma, rechazo del alimento o vómitos, convulsiones, hipotonía/hipertonía, respiración irregular o taquipnea.

Exclusión: no coincide con clínica ni edad clásica de presentación; en los paraclínicos LCR normal, sin alteraciones en ganglios basales.

Definición: alteración a nivel de sistema nervioso secundario a ingesta de metales pesados, solventes y vapores, pesticidas y neurotóxicos de origen natural.

Clínica: confusión, dificultad para la atención, convulsiones, estado de coma.

Exclusión: por historia clínica no tiene antecedentes de exposición a metales.

Definición: aumento de la presión intracraneal que puede ser ocasionada por: contusión/TCE, hemorragia, isquemia, neoplasia, encefalitis, meningitis, hiponatremia, posradiación, absceso, trombosis del seno dural.

Clínica: triada de inicio: cefalea, vómitos y edema de papila. Progresión clínica con disminución del nivel de conciencia, crisis convulsivas.

Exclusión: LCR y virales en LCR, electrólitos séricos normales. RM y TAC que descartan sangrado, neoplasia intracraneal, trombosis. No tiene antecedente de radiación, contusión-traumatismo ni datos de fractura en imagen.

Definición: la hemorragia intracerebral es una colección de sangre dentro del parénquima cerebral, producida por una rotura vascular. Entre las causas más comunes se encuentran: malformación arteriovenosa, traumatismo, aneurisma.

Clínica: comienza súbitamente con dolor de cabeza seguido de pérdida progresiva de funciones neurológicas (debilidad, hemiparesia, pérdida del habla o de la visión y confusión). Son frecuentes náuseas, vómitos, crisis convulsivas y pérdida de consciencia que puede ocurrir en pocos minutos. Exclusión: la clínica no empata con la presentada en la paciente. Esta causa fue descartada por estudios de imagen y de laboratorio (perfil de coagulación, TAC y RM sin datos de hemorragia o isquemia).

Definición: progresión tumoral hacia estructuras del sistema nervioso.

Clínica: cefalea, náuseas y vómitos, irritabilidad, rigidez de nuca, papiledema, afectación de pares craneales (sobre todo III, IV, VI y VII). Otras manifestaciones menos frecuentes son las convulsiones, el síndrome hipotalámico-obesidad por afectación del centro de saciedad, la infiltración de la médula espinal o la paraparesia secundaria a la afectación de la raíces nerviosas de la cola de caballo. En general, la afectación del SNC es más frecuente en las LMA mielomonocítica o monocítica (LMA-M4 y LMA-M5).

Exclusión: descartada por forma de aparición de los síntomas; además, punción lumbar sin datos de infiltración como presencia de células tumorales.

LCR: líquido cefalorraquídeo; LMA: leucemia mielocítica aguda; RM: resonancia magnética; SNC: sistema nervioso central; SNP: sistema nervioso periférico; TAC: tomografía axial computada; TCE: traumatismo craneoencefálico. 
Además, los efectos de los esteroides por lo general desaparecen en el transcurso de 3 a 5 semanas y la paciente experimentó remisión de sus síntomas neurológicos en las primeras 2 semanas de iniciado el cuadro clínico neurológico.

La encefalopatía causada por quimioterapia es la forma de expresión más frecuente de neurotoxicidad por quimioterapia sobre el sistema nervioso central; puede acompañarse de focalización neurológica, de crisis generalizadas, o ambas. Su curso clínico puede ser agudo o crónico; este último produce un cuadro de demencia de tipo subcortical. Algunos quimioterápicos y tratamientos de soporte con efecto neurotóxico potencial sobre el sistema nervioso central se enlistan en el Cuadro 3.41,42 Días antes del cuadro neurológico recibió tratamiento con vincristina y L-asparaginasa; sin embargo, los síntomas no coincidieron con los que suelen presentarse como efecto neurológico secundario a la administración de esos medicamentos. En específico, el uso de L-asparaginasa no se relaciona directamente con síntomas neurológicos, aunque si se le relaciona indirectamente como desencadenante del cuadro clínico de pancreatitis que originó el cuadro convulsivo.

La infiltración neoplásica implica la progresión de la enfermedad hacia estructuras del sistema nervioso. Clínicamente se caracteriza por cefalea, náuseas, vómitos, irritabilidad, rigidez de nuca, papiledema o afectación de pares craneales (sobre todo III, IV, VI y VII). Otras manifestaciones menos frecuentes son crisis convulsivas, infiltración de la médula espinal o paraparesia secundaria a la afectación de las raíces nerviosas de la cola de caballo. En general, la afectación del sistema nervioso central es más frecuente en las leucemias mieloides agudas mielomonocítica o monocítica (LMAM4 y LMA-M5). ${ }^{43}$. Esta causa se descartó por la ausencia de células tumorales en el líquido cefalorraquídeo.
Cuadro 3. Medicamentos usados en quimioterapia oncológica que pueden ocasionar síntomas neurológicos

\begin{tabular}{|c|c|}
\hline Medicamento & Alteración neurológica \\
\hline Cisplatino & $\begin{array}{l}\text { Hipoacusia neurosensorial, acú- } \\
\text { fenos, vestibulopatía, signo de } \\
\text { Lhermitte, crisis comiciales, } \\
\text { infartos isquémicos }\end{array}$ \\
\hline Carboplatino & Encefalopatía \\
\hline Oxaliplatino & Ototoxicidad \\
\hline Ifosfamida & $\begin{array}{l}\text { Encefalopatía (alteración del nivel } \\
\text { de conciencia, agitación, sínto- } \\
\text { mas cerebelosos, parkinsonismo } \\
\text { y crisis) }\end{array}$ \\
\hline Melfalán & Encefalopatía \\
\hline Nitrosourea & Encefalopatía, mielopatía \\
\hline Busulfán & Crisis comiciales \\
\hline Metotrexato & $\begin{array}{l}\text { Meningitis aséptica, mielitis trans- } \\
\text { versa, encefalopatía aguda, } \\
\text { subaguda o crónica }\end{array}$ \\
\hline Citarabina & $\begin{array}{c}\text { Síndrome cerebeloso agudo, } \\
\text { mielopatía, encefalopatía, me- } \\
\text { ningitis aséptica, aracnoiditis }\end{array}$ \\
\hline 5-fluorouracilo & Síndrome cerebeloso agudo \\
\hline Fludarabina & $\begin{array}{l}\text { Encefalopatía, crisis, ceguera } \\
\text { cortical, coma }\end{array}$ \\
\hline Vincristina & Neuropatías craneales \\
\hline Etopósido & $\begin{array}{l}\text { Cefalea, crisis, alteración del } \\
\text { nivel de conciencia }\end{array}$ \\
\hline Ácido retinoico (ATRA) & $\begin{array}{l}\text { Hipertensión intracraneal idio- } \\
\text { pática }\end{array}$ \\
\hline Bevacizumab & $\begin{array}{l}\text { Leucoencefalopatía posterior } \\
\text { reversible }\end{array}$ \\
\hline
\end{tabular}

Los datos clínicos y radiológicos mencionados permitieron considerar que todos los síntomas fueron producto de la encefalopatía pancreática, aun cuando la disminución de las enzimas pancreáticas inició antes de la aparición de los síntomas neurológicos, como se describe en otros reportes. Se continuó con el tratamiento sintomático de la pancreatitis hasta el egreso de la paciente de terapia intensiva.

\section{CONCLUSIONES}

La pancreatitis aguda es un padecimiento grave con altas tasas de morbilidad y mortalidad. Hasta 
la fecha el tratamiento continúa siendo el manejo médico con enfoque en los síntomas y tratamiento del paciente en ayuno para la disminución de la estimulación pancreática durante el proceso agudo de inflamación. Existen casos graves que requieren, como parte del soporte, intubación y tratamiento aminérgico en los intentos por restaurar la homeostasis del paciente.

Las complicaciones graves que se presentan en los pacientes pediátricos que cursan con pancreatitis, en especial pancreatitis grave, obligan a establecer un diagnóstico diferencial minucioso. La pancreatitis aguda en pacientes con factores de riesgo y datos clínicos compatibles con encefalopatía requiere de la evaluación de un equipo multidisciplinario para detectar de forma temprana y oportuna la causa de los síntomas y establecer el tratamiento médico apropiado; esto con el propósito de evitar la progresión de edema cerebral, daño neurológico y muerte.

En el caso de nuestra paciente se realizó un estudio sistemático tanto por laboratorio como paraclínico de los diagnósticos diferenciales que, por sus antecedentes, pudieran haber propiciado los síntomas neurológicos (isquemia, estado hiperosmolar, hipocalcemia, acidosis metabólica por diabetes secundaria a la pancreatitis, encefalitis infecciosa, síndrome neuroléptico maligno, encefalopatía metabólica o tóxica, lesión ocupativa intracraneal, hemorragia o isquemia intracraneal e infiltración tumoral) quedando como principal opción diagnóstica la encefalopatía pancreática.

La encefalopatía pancreática parece ser el reflejo clínico de la interacción entre sustancias proinflamatorias del sistema inmunológico, liberadas durante la cascada inflamatoria característica de la pancreatitis aguda, y el sistema nervioso central. Por este motivo es de primordial importancia considerar este diagnóstico en todo paciente que curse con sintomatología neurológica aguda asociada con un cuadro de afección pancreática.

\section{REFERENCIAS}

1. Consuelo Sánchez A, García Aranda JA. Pancreatitis aguda. Bol Med Hosp Infant Mex 2012;69(1):3-10.

2. Etxeberria Lekuona D, Pueyo Royo A, Edurne Arteche D. Pancreatitis Aguda. En libro Electrónico de Temas de Urgencias, Digestivas y Quirúrgicas. www.navarra.es/ home_es/Temas/Portal+de+la+Salud/Profesionales/ Documentacion+y+publicaciones/Otras+publicaciones/Li bro+electronico+de+temas+de+urgencia/

3. Cerda Cortaza L. Análisis de las nuevas clasificaciones de la pancreatitis aguda. Cirujano General 2013;35(Supl.1):1617.

4. Lautz TB, Chin AC, Radhakrishnan J. Acute pancreatitis in childen: spectrum of disease and predictors of severity. J PediatricSurgery 2011;46(6):1149-9.

5. Casal L, Meana J, Karatanasópuloz C. Pancreatitis Aguda: Revisión. Revista de Posgrado de la VI cátedra de medicina 2002;112:5-20.

6. Vera O. Manejo y tratamiento de la pancreatitis aguda en la unidad de cuidados intensivos. Artículo de revisión. Rev Med 2011;17:47-59.

7. Marruecos SL. Pancreatitis aguda. Med Clin 1992;98:69498.

8. Mayer AD, Marshall J. Acute Pancreatitis. New England J Med 1985;312:399-404.

9. Law NM, Freeman ML. Emergency Complications of Acute and Chronic Pancreatitis. Gastroenterology Clinics of North America 2003;32:1169-1194.

10. Sharf B, Bental E. Boon E. Pancreatic encephalopathy. Journal of Neurology 1991;34:357-361.

11. Qian ZY, Miao Y. Therapeutic strategy for severe acute pancreatitis and pancreatic encephalopathy. Zhonghua Wai Ke Za Zhi 2007;45(11):740-1.

12. Ospina Nieto J, López Moncayo H. Pancreatitis Aguda: diez preguntas por responder. Asociación Colombiana de Cirugía, guías de manejo en cirugía. Bogotá, d.c. 2008;45:12-15.

13. Uribe U, Arana Ch, Lorenzana P. Fundamentos de Medicina - Neurología. 2002. Editor Medellin, Colombia: Corporación para Investigaciones Biológicas, 2002: pp. 432-5.

14. Sharf B, Bental E. Pancreatic encephalopathy. Journal of Neurology 1991;34:357-361.

15. Ampo K, Suzuki A, Konishi H, Kiyama H. Induction of Pancreatitis-Associated Protein (PAP) Family Members in Neurons after Traumatic Brain Injury. Journal of neurotrauma 2009;26:1683-1693.

16. Boon P, Reuck de J, Achten E, De Bleecker J. Pancreatic encephalopathy a case report and review of the literature. Clinical Neurology and Neurosurgery 1991;93: 1116-1118. 
17. McEwan DJ. TNF receptor subtype signaling: differences and cellular consequences. Cell Signal 2002;14:477-492.

18. Barone FC, Arvin B, White RF, Miller A, Webb CL, Willette $\mathrm{RN}$. Tumor necrosis factor-alpha. A mediator of focal ischemic brain injury. Stroke 1997;28:1233-1244.

19. Lenzlinger PM, Morganti-Kossmann MC, Laurer HL, McIntosh TK. The duality of the inflammatory response to traumatic brain injury. Mol Neurobiol 2001;24:169-181.

20. Sriram K, O'Callaghan JP. Divergent roles for tumor necrosis factor-alpha in the brain. J. Neuroimmune Pharmacol 2007;2:140-153.

21. Pickering M, O'Connor JJ. Pro-inflammatory cytokines and their effects. Prog Brain Res 2007;163:339-354.

22. Botchkina GI, Meistrell III ME, Botchkina IL, Tracey KJ. Expression of TNF and TNF receptors (p55 and p75) in the rat brain after focal cerebral ischemia. Mol Med 1997;3:765-781.

23. Ravizza T, Gagliardi B, Noé, F, Boer K, Aronica E, Vezzani A. Innate and adaptive immunity during epileptogenesis and spontaneous seizures: evidence from experimental models and human temporal lobe epilepsy. Neurobiol Dis 2008;29:142-160.

24. Schafers M, Sorkin L. Effect of cytokines on neuronal excitability. Neuroscience Lett 2008;437:188-193.

25. Viviani B, Gardoni F, Marinovich M. Cytokines and neuronal ion channels in health and disease. Int Rev Neurobiol 2007;82:247-263.

26. Balosso S, Ravizza T, Aronica E, Vezzani A. The dual role of TNF- $\alpha$ and its receptors in seizures. Exp Neurol 2013;247:267-71.

27. Zhang XP, Tian H. Pathogenesis of pancreatic encephalopathy in severe acute pancreatitis. Hepatobiliary Pancreat Dis Int 2007;6(2):134-40.

28. Casas JD, Diaz R, Valderas $\mathrm{G}$, et al. Prognostic value of $\mathrm{CT}$ in the early assessment of patients with acute pancreatitis. Am J Roentgenol 2004;182(3):569-574.

29. Balosso S, Ravizza T, Aronica E, Vezzani A. The dual role of TNF- $\alpha$ and its receptors in seizures. Exp Neurol 2013;247:267-71.
30. Banfi A. Encephalitis: Which are and how to treat? Rev Chil Infect 2003;20(1):S28-S33.

31. Ruiz M, Santana C. Enfoque práctico para el diagnóstico de los errores congénitos del metabolismo. Acta Pediátrica Española 1998;(56):39-52.

32. Campistol J. congenital errors of metabolism with epileptic seizures during the first years of life. Rev neurol 2002;35:S3S20.

33. Martin E. García M. Enfermedades congénitas del metabolismo en el periodo neonatal (I). Generalidades. Acta Pediatr Esp 2006;64(8):391-395.

34. Arrollo H, Fernández M. Tóxicos ambientales y su efecto sobre el neurodesarrollo. Medicina (Buenos Aires) 2013;73(1):93-102.

35. Nava C, Méndez M. Efectos neurotóxicos de metales pesados (cadmio, plomo, arsénico y talio). Arch Neurociencias Mex 2011;(16):140.

36. Gaona V. Cefaleas por hipertensión intracraneana. Rev Med Hondur 2014;82(2):1-108.

37. Betancourt $Y$, Jiménez B. Pseudotumor cerebral pediátrico. Rev Neurol 2006;42(3):S67-S73.

38. Ortega A, Romero F. Tumores del sistema nervioso central en la infancia: aspectos clinicopatológicos. Rev Neurol 2004;38(6):554-564.

39. Hidalgo A. Pancreatitis Aguda y sus complicaciones. Caracas: UCV., Consejo de Desarrollo Científico y Humanístico, 2006. pp. 55-56.

40. Gil Lemus L, Sarmiento Suárez M. Psicosis inducida por esteroides. Revista colombiana de psiquiatría 2007;(36):542550.

41. Vieitez J. Calleja S. Protocolo diagnóstico y terapéutico de la neurotoxicidad por citostáticos. Encycl Méd Chir 2001;3117-3122.

42. Coeffic $D$, Antoine $E$, Khavat D. Quimioterapia antitumoral. Encycl Méd Chir 2002;(6):2,1-7.

43. Cano I, Enríquez N. Tumores de fosa posterior en pacientes pediátricos y su correlación clínica, radiológica y anatomopatológica. Anales de radiología México 2010;4:185-205. 